\title{
Hand-Held Femtogram Detection of Hazardous Picric Acid with 2 Hydrophobic Ag Nanopillar SERS Substrates and Mechanism of 3 Elasto-Capillarity
}

Hakonen, Aron; Wang, FengChao; Andersson, Per Ola; Wingfors, Håkan; Rindzevicius, Tomas; Schmidt, Michael Stenbæk; Soma, Venugopal Rao ; Xu, Shicai ; Li, YingQi ; Boisen, Anja

Total number of authors:

11

Published in:

ACS Sensors

Link to article, DOI:

10.1021/acssensors.6b00749

Publication date:

2017

Document Version

Peer reviewed version

Link back to DTU Orbit

Citation $(A P A)$ :

Hakonen, A., Wang, F., Andersson, P. O., Wingfors, H., Rindzevicius, T., Schmidt, M. S., Soma, V. R., Xu, S., Li, Y., Boisen, A., \& Wu, H. (2017). Hand-Held Femtogram Detection of Hazardous Picric Acid with 2

Hydrophobic Ag Nanopillar SERS Substrates and Mechanism of 3 Elasto-Capillarity. ACS Sensors, 2(2), 198202. https://doi.org/10.1021/acssensors.6b00749

\section{General rights}

Copyright and moral rights for the publications made accessible in the public portal are retained by the authors and/or other copyright owners and it is a condition of accessing publications that users recognise and abide by the legal requirements associated with these rights.

- Users may download and print one copy of any publication from the public portal for the purpose of private study or research.

- You may not further distribute the material or use it for any profit-making activity or commercial gain

- You may freely distribute the URL identifying the publication in the public portal 


\title{
Handheld femtogram detection of hazardous Picric acid with hydrophobic Ag nanopillar SERS substrates and mechanism of elasto-capillarity
}

\author{
Aron Hakonen*a,b, FengChao Wangc, Per Ola Andersson ${ }^{\text {d,e }}$, Håkan Wingfors ${ }^{\mathrm{d}}$, Tomas Rin- \\ dzevicius ${ }^{\mathrm{f}}$, Michael Stenbæk Schmidt ${ }^{\mathrm{f}}$, Venugopal Rao Soma ${ }^{\mathrm{g}}$, Shicai Xu ${ }^{\mathrm{h}}$, YingQi Li ${ }^{\mathrm{c}}$, Anja Boi- \\ $\operatorname{sen}^{\mathrm{f}}$ and HengAn $\mathrm{Wu}^{\mathrm{c}}$ \\ a. Department of Physics, Chalmers University of Technology, S-412 96 Göteborg, Sweden. \\ b. SP Technical Research Institute of Sweden, Chemistry, Materials and Surfaces, Box 857, SE-501 15 Borås, Sweden. \\ c. Chinese Academy of Sciences Key Laboratory of Mechanical Behavior \& Design of Materials, Department of Mod- \\ ern Mechanics, University of Science \& Technology of China, Hefei, Anhui 230027, China. \\ d. Swedish Defense Research Agency FOI, CBRN Defence \& Security, SE-90182 Umeå, Sweden. \\ e. Department of Engineering Sciences, Uppsala University, P.O. Box 534, SE-751 21 Uppsala, Sweden. \\ f. DTU Nanotech, Technical University of Denmark, Department of Micro- and Nanotechnology, Ørsteds Plads, \\ Building 345 east, 2800 Kgs. Lyngby \\ g. Advanced Centre of Research in High Energy Materials (ACRHEM), University of Hyderabad, Hyderabad 50oo46, \\ Telangana, India. \\ h. Shandong Provincial Key Laboratory of Biophysics, College of Physics and Electronic Information, Dezhou Uni- \\ versity, Dezhou 253023, China.
}

Supporting Information Available: The following files are available free of charge: Movie S1, MD simulation of the wetting; Movie S2, MD simulation of the evaporation; Table $S_{1}$, Raman peaks

\begin{abstract}
Picric acid (PA) is a severe environmental and security risk due to its unstable, toxic and explosive properties. It is also challenging to detect in trace amounts and insitu because of its highly acidic and anionic character. Here we assess sensing of PA under non-laboratory conditions using surface-enhanced Raman scattering (SERS) silver nanopillar substrates and hand-held Raman spectroscopy equipment. The advancing elasto-capillarity effects are explained by molecular dynamics simulations. We obtain a SERS PA detection limit on the order of $20 \mathrm{ppt}$, corresponding attomole amounts, which together with the simple analysis methodology demonstrates that the presented approach is highly competitive for ultrasensitive analysis in the field.
\end{abstract}

Picric acid (PA) or 2,4,6-trinitrophenol (TNP), is an old and well-known high explosive but mounting security concerns has led to a renewed interest and an outburst of publications, for example. ${ }^{1} \mathrm{PA}$ is highly unstable, in addition to being toxic and cancerous and, therefore, a serious security liability. ${ }^{\text {1a-v }}$ There is an urgent need for highly sensitive PA sensors for water samples since large amounts has been released from industrial use, leading to accumulation in rivers, lakes and ground water. ${ }^{1 \mathrm{a}-\mathrm{v}}$ The marketing and use of some explosive precursors has recently been regulated within the European Union (EU No 98/2013) to prevent illicit manufacture. However, some explosives, including PA, can still be synthesized from freely available chemicals. PA is a solid with low vapour pressure and a relatively high water solubility $(12.7 \mathrm{~g} / \mathrm{l})$, which makes it difficult to detect in vapour phase at ambient temperatures. PA present as dust is classified as a sensitizing substance and has recently been assigned a new low permissible exposure limit ( $0.1 \mathrm{mg} / \mathrm{m}^{3} 8 \mathrm{hr}$ TWA). To this end, robust, sensitive and selective PA detection methods needs to be developed, both to avert terrorist threats as well as for monitoring environmental pollution. ${ }^{1}$

Most recent works on PA have dealt with the issue of trace detection and sensing, in particular based on fluorescence techniques. ${ }^{1}$ Surface-enhanced Raman scattering (SERS) spectroscopy is widely recognized as an ultrasensitive method to detect e.g. biomolecules ${ }^{2}$ and explosives, ${ }^{3}$ and in particular conjugated nitro-explosives such as TNT and PA. ${ }^{\mathrm{b}}$ Despite this, the first SERS studies of PA appeared only recently. ${ }^{\text {e }, ~} 45$ For example, Stewart et al. 5 demonstrated a detection limit of $20 \mu \mathrm{M}$ PA on positively charged Ag nanoparticles and pointed out the difficulty of measuring anions, such as PA, on SERS active gold or silver due to the negative zeta potential of these metals. The lowest SERS detection limit for PA, $0.46 \mu \mathrm{M}$ using a hybrid silver- magnetite detection scheme, was reported recently. ${ }^{4}$ 
We have recently reported that gold-on-silicon nanopillar SERS substrates exhibit extraordinary properties for detecting the nerve gases VX and Tabun. ${ }^{6}$ We here use similar substrates in which the Au has been replaced by silver. This type

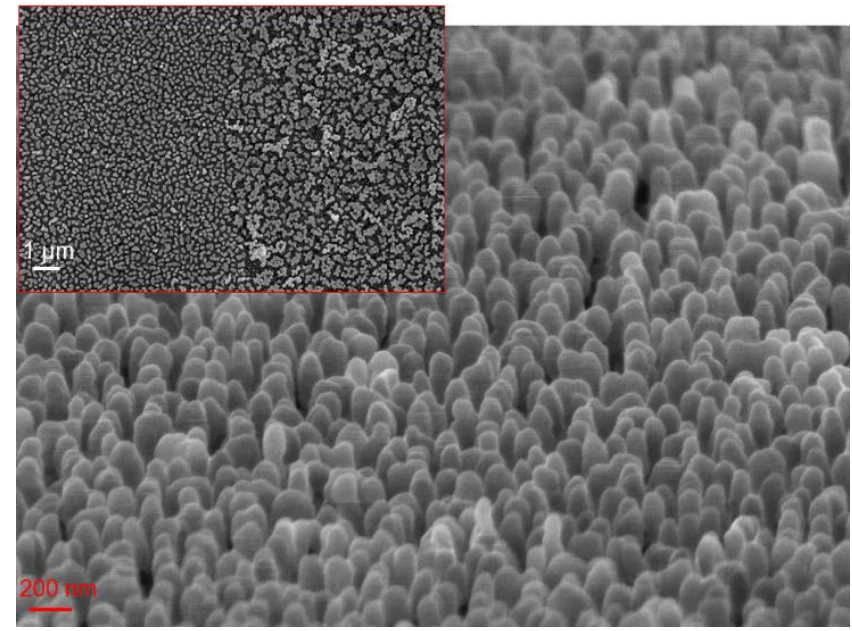

Figure 1. Tilted SEM image of the silver nanopillar SERS substrates used in this study. Inset shows the substrate at an evaporated droplet interface, where the droplet has generated clustering to the right.

of substrate has been described previously ${ }^{7}$ and further optimized. ${ }^{8}$ Briefly, the samples consist of a Si-nanopillar base substrate, obtained through reactive ion etching, covered by $225 \mathrm{~nm}$ evaporated Ag. The resulting "nano-forest"9 of flexible Ag nanopillars, shown in Figure 1, turned out to be less hydrophobic than the gold substrates. Hence, it was easier to place and hold small water based droplets on them with good precision. The droplets almost immediately adhered, similar to the Au-nanopillar case, with high contact angles $\left(120-140^{\circ}\right)$ characteristic of hydrophobic surfaces. If a droplet is placed on a substrate and left to evaporate, elastocapillary forces pulls the nanopillars together, resulting in SERS hot-spot clusters. ${ }^{6}$ This is illustrated by the SEM image inset in Figure 1, which shows the edge between a pristine surface region and a region where a droplet containing a low concentration of PA (o.4 ppb) has dried out. Similar hot-spot generating clustering has been observed previously on several gold and silver substrates, e.g. in. ${ }^{10}$ The clustering effect also creates a macroscopically visible spot on the substrates (ca. $1.5 \mathrm{~mm}$ diameter from a $2 \mu \mathrm{l}$ droplet). Such spots can be clearly seen on silver-based substrates under normal lighting conditions, whereas Au-substrates require very bright light. Figure 2 illustrates how we used a handheld Raman instrument (Serstech 100 Indicator) to measure SERS from PA (molecular model in Fig. 2 inset) on the Ag nanopillar substrates. Rapid droplet adhesion, clearly visible drying stains and the possibility to perform handheld measurements is clearly a powerful and convenient combination for SERS analysis in the field and outside dedicated laboratories.

The SERS spectrum in figure $3 \mathrm{a}$ from an evaporated $2 \mu \mathrm{l}$ droplet with 20 ppb PA in water show several distinctive peaks, of which the major ones are at: 820 and $1332 \mathrm{~cm}^{-1}$ and are both related to vibrational modes of the $\mathrm{NO}_{2}$-group. ${ }^{11}$ In table $\mathrm{S}_{1}$ all identified peaks are listed and compared with literature SERS and Raman studies, 5, 11a and a high correlation is seen, especially with the SERS study. Fig. 3 b shows the 820 $\mathrm{cm}^{-1}$ peak at different concentrations of Picric acid (o - 20 $\mathrm{ppb}$, averaged spectra, $\mathrm{n}_{\mathrm{Tot}}=\mathbf{2 2}$ ). The measurements were acquired as shown in Fig. 2, with experimental parameters: $785 \mathrm{~nm} / 165 \mathrm{~mW}$ laser, $2 \mathrm{~s}$ acquisition time, $50 \mu^{2}$ spotsize, numerical aperture of the outermost lens was o.3. A nice trend is seen in the calibration curve (Fig. 3c), and as typically seen in SERS a rapidly declining signal, which as commonly, is likely due to hot-spot saturation. ${ }^{12}$ The lowest explicitly measured concentration was $0.04 \mathrm{ppb}$, and the $2 \mu \mathrm{l}$ droplet equals to a total amount

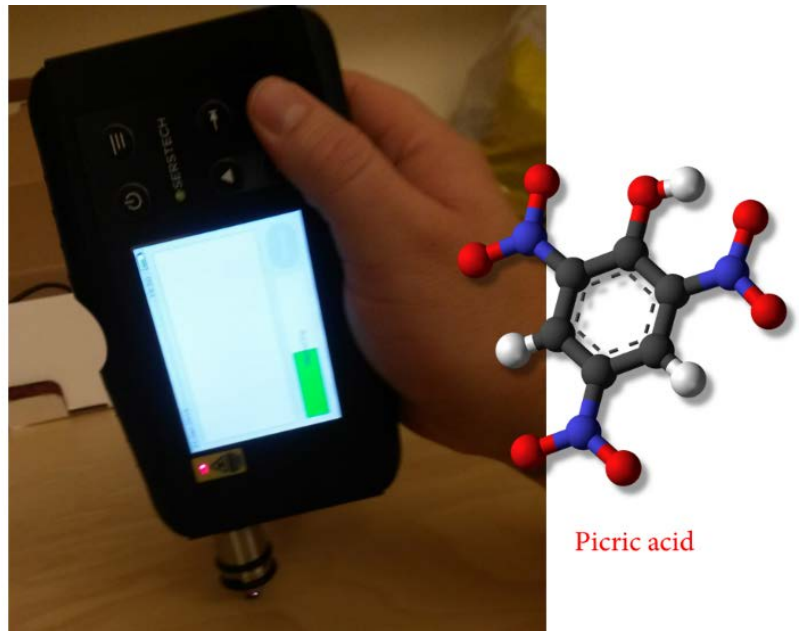

Figure 2. The Raman instrument during handheld measurement on a SERS substrate and a molecular model of Picric acid.

of 8 o femtogram or 350 attomol. From zero level noise $(\sigma)$ and the slope $(\mathrm{k})$ to the $0.04 \mathrm{ppb}$ level the detection limit $(\mathrm{LOD}=3 \sigma / \mathrm{k})^{13}$ were calculated to be $18 \mathrm{ppt}$ (parts per trillion; total amount 36 femtogram, 16o attomol), and limit of quantification (LOQ) to o.06 ppb.For a brief comparison with literature, the previously mentioned SERS study showed a LOD of $0.46 \mu \mathrm{M}$ which equals about $110 \mathrm{ppb}$, i.e. approximately $3-4$ orders of magnitude higher. Looking at other techniques a very impressive LOD was demonstrated recently by Malik et al., ${ }^{1 \mathrm{~m}} 7 \mathrm{ppt}$ or $3^{1} \mathrm{pM}$ and the lowest explicitly detected PA concentration was $200 \mathrm{pM}$ or $46 \mathrm{ppt}$, i.e. very similar results as in present study (18 ppt and $40 \mathrm{ppt})$. The technique used by Malik et al. was fluorescence quenching based, which is by far the most used sensing method for Picric acid. Additionally, for our most impressive results regarding totally loaded amounts of PA comparing numbers are not present in the Malik et al. study. For a brief comparison with the in-laboratory gold standard for everything difficult to measure mass-spectrometry, which quite commonly achieves detection limits in the femtogram range, however, with a quick overview of literature picogram detection of Picric acid was the best to be found. ${ }^{14}$ 


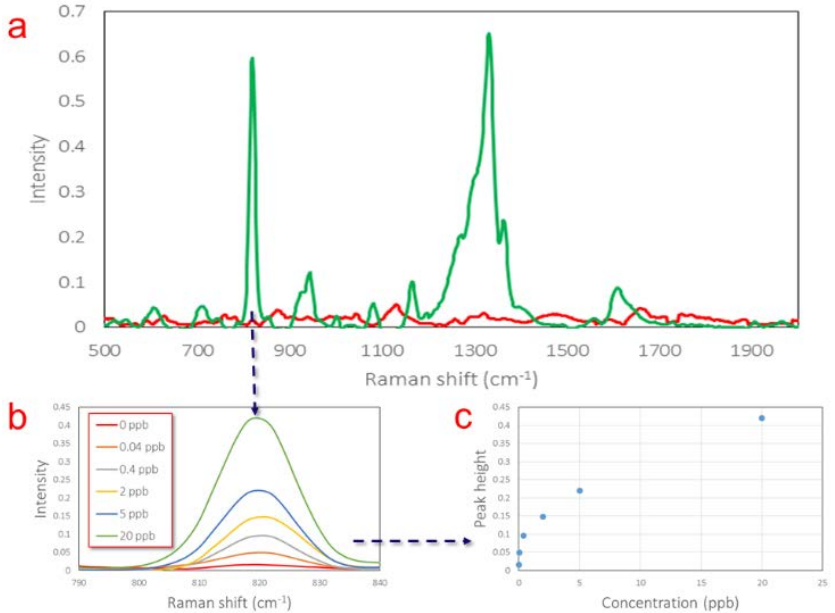

Figure 3.

a) Handheld instrument Serstech SERS spectrum of Picric acid ( $2 \mu \mathrm{l}, 20 \mathrm{ppb})$ and background (red). b) Concentration dependence of the $820 \mathrm{~cm}^{-1}$ peak. c) PA calibration curve.
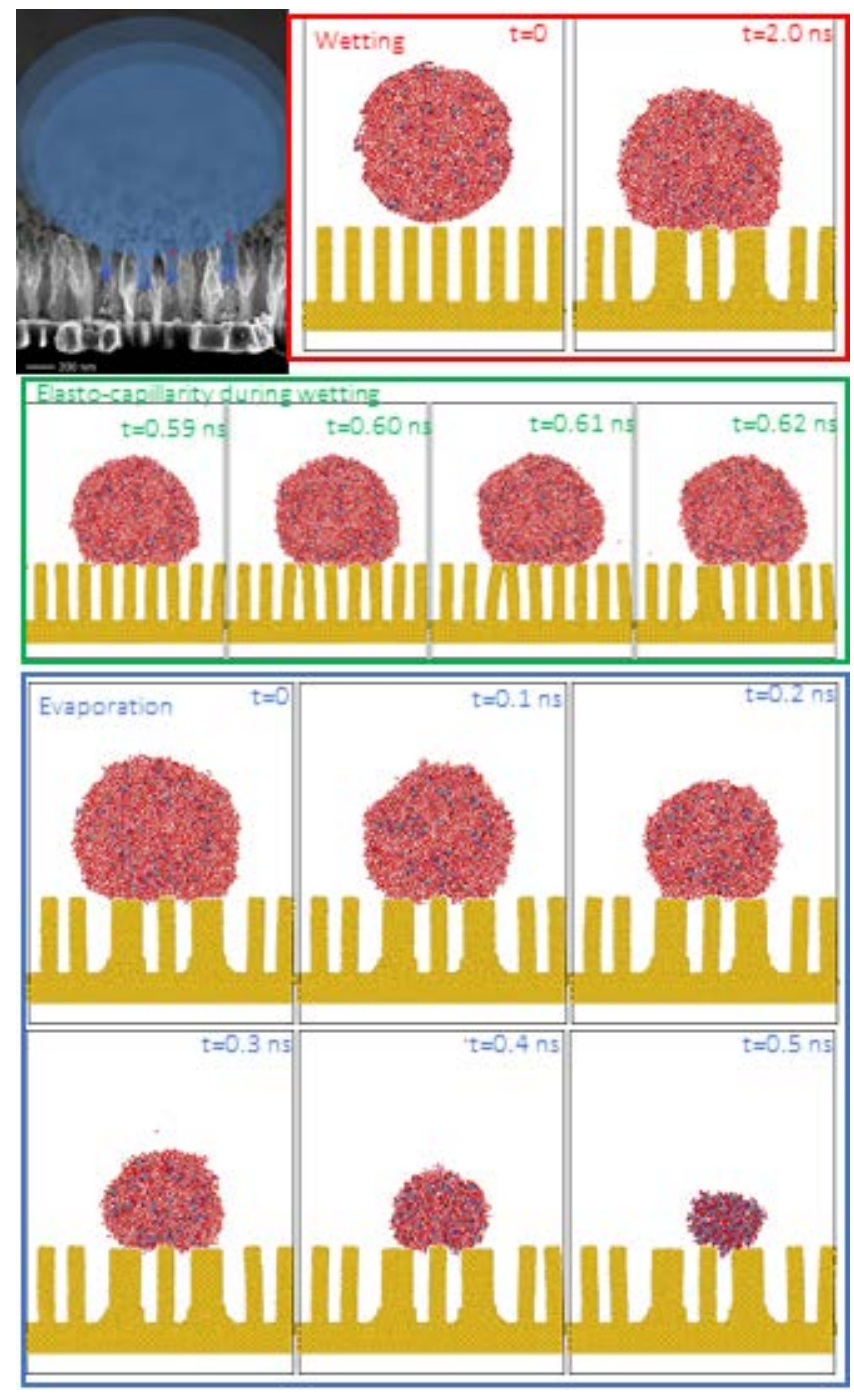

Figure 4.

Top: profile SEM image of the Ag nanopillar substrates. Illustrated on top is an evaporating water droplet. Red panel: MD snapshots of the droplet of PA solution wetting on Ag pillared surface. Balls with different colors were used to denote different type of atoms: Oxygen (red);
Hydrogen (white); Carbon (grey); Nitrogen (blue); Ag (yellow). Left: Initial state; Right: Equilibrium state at 2.0 ns. Green panel: clustering of two Ag nanopillars due to the elasto-capillarity interactions. Blue panel: MD snapshots of evaporation of a droplet of PA solution on Ag nanopillars.

Further insights into the nanofluidics of PA/water droplets on $\mathrm{Ag}$ nanopillar surfaces were investigated by molecular dynamics (MD) simulations. ${ }^{15}$ MD simulations were carried out to study the wetting and evaporation process on an $\mathrm{Ag}$ nanopillared surface, as shown in Fig. 4. Each Ag nanopillar has a height of $4.09 \mathrm{~nm}$ and a width of $0.82 \mathrm{~nm}$ and the $\mathrm{Ag}$ $\mathrm{Ag}$ interactions are modelled by (EAM) potential. ${ }^{16} 5$,ooo water molecules and 100 PA molecules were mixed together using Packmol. ${ }^{17}$ Water TIP $4 \mathrm{P} / 2005$ model was used ${ }^{18}$ and PA was described by the Merck Molecular ForceField. ${ }^{19}$ The temperature of the system was maintained at $300 \mathrm{~K}$ using a Berendsen thermostat. A timestep of 1.o fs was used. All the MD simulations were performed using LAMMPS. ${ }^{20}$ We also calculated the surface tension of water and PA solution using Kirkwood-Buff formula. ${ }^{21}$ Our MD results show that the surface tension for pure water and PA/water solution are 62.8 and $72.5 \mathrm{mN} / \mathrm{m}$, respectively, i.e. the PA molecules increases the surface tension compared with pure water.

The droplet of PA solution, with a diameter of about 9.0 $\mathrm{nm}$, was brought to connect with the pillared surface and then started to wet the surface. Due to the elasto-capillary interactions ${ }^{22}$ between the liquid and $\mathrm{Ag}$, the $\mathrm{Ag}$ nanopillars show bending deformations, as shown in Fig. 4 (Green panel) and supporting movie S1. If two nanopillars are close enough, they collapse which results in the clustering, as shown in Fig. 4. After that, the evaporation simulation was conducted, starting with the equilibrium state obtained in the simulations of the wetting process, and evaporation evolved as shown in Fig. 4 (Blue panel) and movie S2. The procedure for evaporation has been described in previous work. ${ }^{23}$ Also shown in previous work is that the evaporation could lead to further bending of nanopillars, ${ }^{15}$ which may enhance the clustering of Ag nanopillars. However, we could not observe such result in this evaporation case. The reason may be that the clustering in the wetting process increases the bending stiffness of Ag nanopillars. Nevertheless, these MD simulation results demonstrate that the elasto-capillary effect is crucial for the clustering of Ag pillars observed in experiments.

In conclusion, Picric acid is an interesting molecule in many aspects affecting human sustainability and living on many levels. Its high acidity and negative charge in most natural environments presents analytical challenges, especially for plasmonic based sensing with gold or silver substrates. We demonstrate the first example of ultra-sensitive SERS of Picric acid on bare silver substrates. Particular nanofluidics and plasmonics are benefitted from, leading to enrichment of PA molecules in SERS hot-spots. Experiments and molecular dynamics simulations show that elastocapillarity is crucial for these signal accumulating effects. With a small and simple hand-held device sensitivity and detection is in level with or even better than state of the art techniques for Picric acid today, including massspectrometry. Low femtogram detection is achieved from $2 \mu \mathrm{l}$ droplets of 40 ppt Picric acid. 


\section{ASSOCIATED CONTENT}

\section{Supporting Information}

The Supporting Information is available free of charge on the ACS Publications website. Supporting movie S1, S2 and table S1.

\section{AUTHOR INFORMATION}

\section{Corresponding Author}

* E-mail address: aron.hakonen@sp.se

Notes

The authors declare no competing financial interests.

\section{ACKNOWLEDGMENT}

$\mathrm{AH}$ and POA acknowledges support from the Swedish Foundation for Strategic Research (project RMA11-0037 and FOI project 410-E4272).

\section{REFERENCES}

1. (a) Li, X. G.; Liao, Y. Z.; Huang, M. R.; Strong, V.; Kaner, R. B., Ultra-sensitive chemosensors for Fe(III) and explosives based on highly fluorescent oligofluoranthene. Chem. Sci. 2013, 4 (5), 1970-1978; (b) Nagarkar, S. S.; Joarder, B.; Chaudhari, A. K.; Mukherjee, S.; Ghosh, S. K., Highly Selective Detection of Nitro Explosives by a Luminescent Metal-Organic Framework. Angew. Chem.-Int. Edit. 2013, 52 (10), 2881-2885; (c) Arora, P. K.; Srivastava, A.; Singh, V. P., Bacterial degradation of nitrophenols and their derivatives. J. Hazard. Mater. 2014, 266, 42-59; (d) Banerjee, D.; Hu, Z. C.; Li, J., Luminescent metal-organic frameworks as explosive sensors. Dalton Trans. 2014, 43 (28), 10668-10685; (e) Enkin, N.; Sharon, E.; Golub, E.; Willner, I., Ag Nanocluster/DNA Hybrids: Functional Modules for the Detection of Nitroaromatic and RDX Explosives. Nano Lett. 2014, 14 (8), 4918-4922; (f) Gole, B.; Bar, A. K.; Mukherjee, P. S., Modification of Extended Open Frameworks with Fluorescent Tags for Sensing Explosives: Competition between Size Selectivity and Electron Deficiency. Chem.-Eur. J. 2014, 20 (8), 2276-2291; (g) Kaur, S.; Bhalla, V.; Vij, V.; Kumar, M., Fluorescent aggregates of heterooligophenylene derivative as "no quenching" probe for detection of picric acid at femtogram level. J. Mater. Chem. C 2014, 2 (20), 3936-3941; (h) Nagarkar, S. S.; Desai, A. V.; Ghosh, S. K., A fluorescent metal-organic framework for highly selective detection of nitro explosives in the aqueous phase. Chem. Commun. 2014, 50 (64), 8915-8918; (i) Dutta, P.; Saikia, D.; Adhikary, N. C.; Sen Sarma, N., Macromolecular Systems with MSA-Capped CdTe and CdTe/ZnS Core/Shell Quantum Dots as Superselective and Ultrasensitive Optical Sensors for Picric Acid Explosive. ACS Appl. Mater. Interfaces 2015, 7 (44), 2477824790; (j) Gogoi, B.; Paul, N.; Chowdhury, D.; Sen Sarma, N., Instant detection of picric acid vapour by developing layer by layer polymer detectors and an electronic prototype. J. Mater. Chem. C 2015, 3 (42), 11081-11089; (k) Joarder, B.; Desai, A. V.; Samanta, P.; Mukherjee, S.; Ghosh, S. K., Selective and Sensitive Aqueous-Phase Detection of 2,4,6-Trinitrophenol (TNP) by an Amine-Functionalized Metal-Organic Framework. Chem.-Eur. J. 2015, 21 (3), 965-969; (l) Lin, L. P.; Rong, M. C.; Lu, S. S.; Song, X. H.; Zhong, Y. X.; Yan, J. W.; Wang, Y. R.; Chen, X., A facile synthesis of highly luminescent nitrogen-doped graphene quantum dots for the detection of 2,4,6-trinitrophenol in aqueous solution. Nanoscale 2015, 7 (5), 1872-1878; (m) Malik, A. H.; Hussain, S.; Kalita, A.; Iyer, P. K., Conjugated Polymer Nanoparticles for the Amplified Detection of Nitro-explosive Picric Acid on Multiple Platforms. ACS Appl. Mater. Interfaces
2015, 7 (48), 26968-26976; (n) Rong, M. C.; Lin, L. P.; Song, X. H.; Zhao, T. T.; Zhong, Y. X.; Yan, J. W.; Wang, Y. R.; Chen, X., A Label-Free Fluorescence Sensing Approach for Selective and Sensitive Detection of 2,4,6-Trinitrophenol (TNP) in Aqueous Solution Using Graphitic Carbon Nitride Nanosheets. Anal. Chem. 2015, 87 (2), 1288-1296; (o) Sanda, S.; Parshamoni, S.; Biswas, S.; Konar, S., Highly selective detection of palladium and picric acid by a luminescent MOF: a dual functional fluorescent sensor. Chem. Commun. 2015, 51 (30), 6576-6579; (p) Shanmugaraju, S.; Mukherjee, P. S., Self-Assembled Discrete Molecules for Sensing Nitroaromatics. Chem.-Eur. J. 2015, 21 (18), 6656-6666; (q) Vishnoi, P.; Sen, S.; Patwari, G. N.; Murugavel, R., Charge transfer aided selective sensing and capture of picric acid by triphenylbenzenes. New J. Chem. 2015, 39 (2), 886-892; (r) Ye, J. W.; Zhao, L. M.; Bogale, R. F.; Gao, Y.; Wang, X. X.; Qian, X. M.; Guo, S.; Zhao, J. Z.; Ning, G. L., Highly Selective Detection of 2,4,6-Trinitrophenol and Cu2+ Ions Based on a Fluorescent Cadmium-Pamoate Metal-Organic Framework. Chem.-Eur. J. 2015, 21 (5), 2029-2037; (s) Zhang, C. Q.; Sun, L. B.; Yan, Y.; Li, J. Y.; Song, X. W.; Liu, Y. L.; Liang, Z. Q., A luminescent cadmium metal-organic framework for sensing of nitroaromatic explosives. Dalton Trans. 2015, 44 (1), 230-236; (t) Hu, Y. L.; Ding, M. L.; Liu, X. Q.; Sun, L. B.; Jiang, H. L., Rational synthesis of an exceptionally stable Zn(II) metalorganic framework for the highly selective and sensitive detection of picric acid. Chem. Commun. 2016, 52 (33), 5734-5737; (u) Pal, A.; Sk, M. P.; Chattopadhyay, A., Conducting Carbon DotPolypyrrole Nanocomposite for Sensitive Detection of Picric acid. ACS Appl. Mater. Interfaces 2016, 8 (9), 5758-5762; (v) Santra, D. C.; Bera, M. K.; Sukul, P. K.; Malik, S., Charge-TransferInduced Fluorescence Quenching of Anthracene Derivatives and Selective Detection of Picric Acid. Chem.-Eur. J. 2016, 22 (6), 2012-2019; (w) Tanwar, A. S.; Hussain, S.; Malik, A. H.; Afroz, M. A.; Iyer, P. K., Inner Filter Effect Based Selective Detection of Nitroexplosive-Picric Acid in Aqueous Solution and Solid Support Using Conjugated Polymer. ACS Sens. 2016, 1 (8), 10701077.

2. (a) Brule, T.; Bouhelier, A.; Dereux, A.; Finot, E., Discrimination between Single Protein Conformations Using Dynamic SERS. ACS Sens. 2016, 1 (6), 676-680; (b) Chang, H. J.; Kang, H. M.; Ko, E.; Jun, B. H.; Lee, H. Y.; Lee, Y. S.; Jeang, D. H., PSA Detection with Femtomolar Sensitivity and a Broad Dynamic Range Using SERS Nanoprobes and an Area-Scanning Method. ACS Sens. 2016, 1 (6), 645-649.

3. (a) Zapata, F.; Lopez-Lopez, M.; Garcia-Ruiz, C., Detection and identification of explosives by surface enhanced Raman scattering. Appl. Spectrosc. Rev. 2016, 51 (3), 207-242; (b) Hakonen, A.; Andersson, P. O.; Schmidt, M. S.; Rindzevicius, T.; Kall, M., Explosive and chemical threat detection by surfaceenhanced Raman scattering: A review. Anal. Chim. Acta 2015, 893, 1-13; (c) Podagatlapalli, G. K.; Hamad, S.; Rao, S. V., TraceLevel Detection of Secondary Explosives Using Hybrid SilverGold Nanoparticles and Nanostructures Achieved with Femtosecond Laser Ablation. J. Phys. Chem. C 2015, 119 (29), 16972-16983; (d) He, X.; Wang, H.; Li, Z. B.; Chen, D.; Liu, J. H.; Zhang, Q., Ultrasensitive SERS detection of trinitrotoluene through capillarity-constructed reversible hot spots based on $\mathrm{ZnO}-$ Ag nanorod hybrids. Nanoscale 2015, 7 (18), 8619-8626; (e) Wang, C.; Liu, B.; Dou, X., Silver nanotriangles-loaded filter paper for ultrasensitive SERS detection application benefited by interspacing of sharp edges. Sensors and Actuators B: Chemical 2016, 231, 357-364; (f) Chen, J.; Shi, Y.-e.; Zhang, M.; Zhan, J., Diethyldithiocarbamate (DDTC) induced formation of positively charged silver nanoparticles for rapid in situ identification of inorganic explosives by surface enhanced Raman spectroscopy. RSC Advances 2016, 6 (57), 51823-51829; (g) Cecchini, M. P.; Turek, V. A.; Paget, J.; Kornyshev, A. A.; Edel, J. B., Self- 
assembled nanoparticle arrays for multiphase trace analyte detection. Nat. Mater. 2013, 12 (2), 165-171; (h) Shi, Y.-e.; Wang, W.; Zhan, J., A positively charged silver nanowire membrane for rapid on-site swabbing extraction and detection of trace inorganic explosives using a portable Raman spectrometer. Nano Research 2016, 1-11; (i) Hamad, S.; Podagatlapalli, G. K.; Mohiddon, M. A.; Soma, V. R., Cost effective nanostructured copper substrates prepared with ultrafast laser pulses for explosives detection using surface enhanced Raman scattering. Appl. Phys. Lett. 2014, 104 (26), 5; (j) Dasary, S. S. R.; Singh, A. K.; Senapati, D.; Yu, H. T.; Ray, P. C., Gold Nanoparticle Based Label-Free SERS Probe for Ultrasensitive and Selective Detection of Trinitrotoluene. J. Am. Chem. Soc. 2009, 131 (38), 1380613812; (k) Li, J. F.; Huang, Y. F.; Ding, Y.; Yang, Z. L.; Li, S. B.; Zhou, X. S.; Fan, F. R.; Zhang, W.; Zhou, Z. Y.; Wu, D. Y.; Ren, B.; Wang, Z. L.; Tian, Z. Q., Shell-isolated nanoparticle-enhanced Raman spectroscopy. Nature 2010, 464 (7287), 392-395.

4. Caro, C.; Sayagues, M. J.; Franco, V.; Conde, A.; Zaderenko, P.; Gamez, F., A hybrid silver-magnetite detector based on surface enhanced Raman scattering for differentiating organic compounds. Sens. Actuator B-Chem. 2016, 228, 124-133.

5. Stewart, A.; Murray, S.; Bell, S. E. J., Simple preparation of positively charged silver nanoparticles for detection of anions by surface-enhanced Raman spectroscopy. Analyst 2015, 140 (9), 2988-2994.

6. Hakonen, A.; Rindzevicius, T.; Schmidt, M. S.; Andersson, P. O.; Juhlin, L.; Svedendahl, M.; Boisen, A.; Kall, M., Detection of nerve gases using surface-enhanced Raman scattering substrates with high droplet adhesion. Nanoscale 2016, 8 (3), 1305-1308.

7. $\quad$ Schmidt, M. S.; Hubner, J.; Boisen, A., Large Area Fabrication of Leaning Silicon Nanopillars for Surface Enhanced Raman Spectroscopy. Adv. Mater. 2012, 24 (10), OP11-OP18.

8. Wu, K.; Rindzevicius, T.; Schmidt, M. S.; Mogensen, K. B.; Hakonen, A.; Boisen, A., Wafer-Scale Leaning Silver Nanopillars for Molecular Detection at Ultra-Low Concentrations. J. Phys. Chem. C 2015, 119 (4), 2053-2062.

9. Mao, H.; Huang, C.; Wu, W.; Xue, M.; Yang, Y.; Xiong, J.; Ming, A.; Wang, W., Wafer-level fabrication of nanocone forests by plasma repolymerization technique for surface-enhanced Raman scattering devices. Applied Surface Science 2017, 396, 1085-1091.

$10 . \quad$ (a) Lee, S. J.; Morrill, A. R.; Moskovits, M., Hot Spots in Silver Nanowire Bundles for Surface-Enhanced Raman Spectroscopy. Journal of the American Chemical Society 2006, 128 (7), 2200-2201; (b) Hu, M.; Ou, F. S.; Wu, W.; Naumov, I.; Li, X.; Bratkovsky, A. M.; Williams, R. S.; Li, Z., Gold Nanofingers for Molecule Trapping and Detection. Journal of the American Chemical Society 2010, 132 (37), 12820-12822; (c) Zhu, C.; Meng, G.; Zheng, P.; Huang, Q.; Li, Z.; Hu, X.; Wang, X.; Huang, Z.; Li, F.; Wu, N., A Hierarchically Ordered Array of Silver-Nanorod Bundles for Surface-Enhanced Raman Scattering Detection of Phenolic Pollutants. Advanced Materials 2016, 28 (24), 4871-4876.

11. (a) Lewis, I. R.; Daniel, N. W.; Griffiths, P. R., Interpretation of Raman spectra of nitro-containing explosive materials. Part I: Group frequency and structural class membership. Appl. Spectrosc. 1997, 51 (12), 1854-1867; (b) Shaik, U. P.; Hamad, S.; Ahamad Mohiddon, M.; Soma, V. R.; Ghanashyam Krishna, M., Morphologically manipulated Ag/ZnO nanostructures as surface enhanced Raman scattering probes for explosives detection. Journal of Applied Physics 2016, 119 (9), 093103.

12. (a) Hakonen, A.; Svedendahl, M.; Ogier, R.; Yang, Z.J.; Lodewijks, K.; Verre, R.; Shegai, T.; Andersson, P. O.; Käll, M., Dimer-on-mirror SERS substrates with attogram sensitivity fabricated by colloidal lithography. Nanoscale 2015, 7 (21), 9405-
9410; (b) Le Ru, E. C.; Etchegoin, P. G.; Meyer, M., Enhancement factor distribution around a single surface-enhanced Raman scattering hot spot and its relation to single molecule detection. Journal of Chemical Physics 2006, 125 (20), 13.

13. Hakonen, A., Plasmon Enhancement and Surface Wave Quenching for Phase Ratiometry in Coextraction-Based Fluorosensors. Anal. Chem. 2009, 81 (11), 4555-4559.

14. Kauppila, T. J.; Flink, A.; Pukkila, J.; Ketola, R. A., Analysis of nitrogen-based explosives with desorption atmospheric pressure photoionization mass spectrometry. Rapid Commun. Mass Spectrom. 2016, 30 (4), 467-475.

15. Wang, F.; Wu, H., Molecular origin of contact line stick-slip motion during droplet evaporation. Scientific Reports 2015, 5, 17521.

16. Foiles, S. M.; Baskes, M. I.; Daw, M. S., EMBEDDEDATOM-METHOD FUNCTIONS FOR THE FCC METALS CU, AG, AU, NI, PD, PT, AND THEIR ALLOYS. Phys. Rev. B 1986, 33 (12), 7983-7991.

17. Martinez, L.; Andrade, R.; Birgin, E. G.; Martinez, J. M., PACKMOL: A Package for Building Initial Configurations for Molecular Dynamics Simulations. Journal of Computational Chemistry 2009, 30 (13), 2157-2164.

18. Abascal, J. L. F.; Vega, C., A general purpose model for the condensed phases of water: TIP4P/2005. The Journal of Chemical Physics 2005, 123 (23), 234505.

19. Zoete, V.; Cuendet, M. A.; Grosdidier, A.; Michielin, O., SwissParam: A Fast Force Field Generation Tool for Small Organic Molecules. Journal of Computational Chemistry 2011, 32 (11), 2359-2368.

20. Plimpton, S., FAST PARALLEL ALGORITHMS FOR SHORT-RANGE MOLECULAR-DYNAMICS. Journal of Computational Physics 1995, 117 (1), 1-19.

21. Kirkwood, J. G.; Buff, F. P., THE STATISTICAL MECHANICAL THEORY OF SURFACE TENSION. Journal of Chemical Physics 1949, 17 (3), 338-343.

22. Bico, J.; Roman, B.; Moulin, L.; Boudaoud, A., Elastocapillary coalescence in wet hair. Nature 2004, 432 (7018), 690-690.

23. Wang, F. C.; Wu, H. A., Pinning and depinning mechanism of the contact line during evaporation of nanodroplets sessile on textured surfaces. Soft Matter 2013, 9 (24), 5703-5709. 
For TOC only

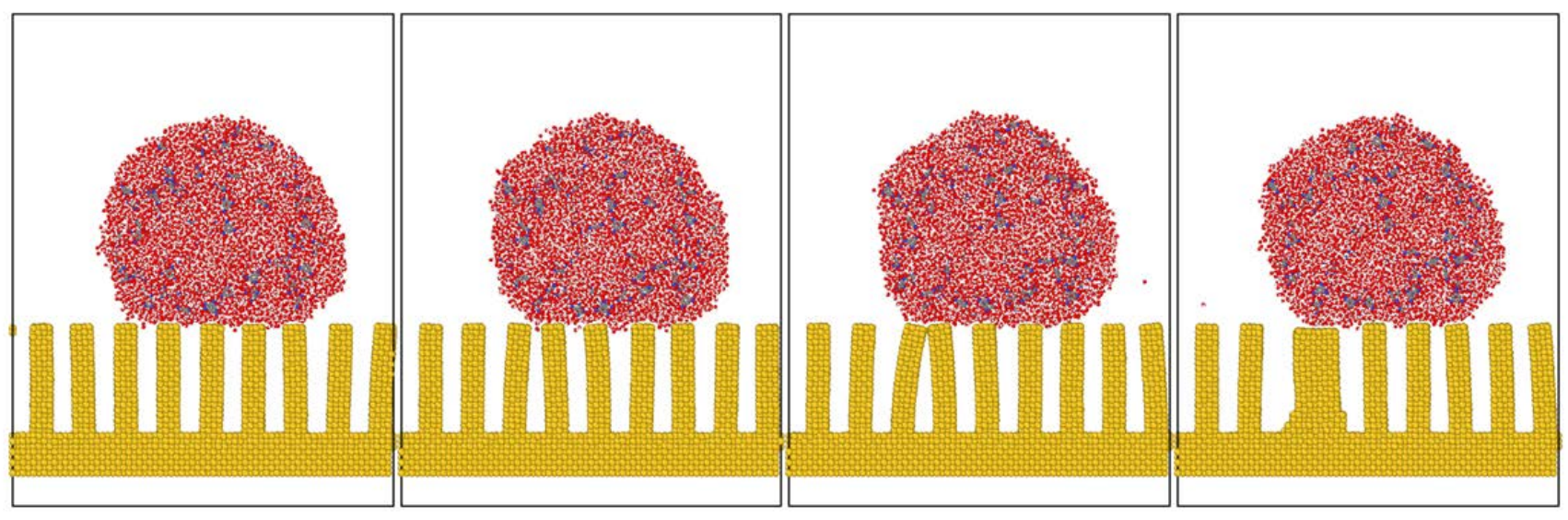

